Open Access

\title{
The ProVIDe study: the impact of protein intravenous nutrition on development in extremely low birthweight babies
}

Frank H. Bloomfield ${ }^{1,2,3,4,5^{*}}$, Caroline A. Crowther ${ }^{1,6}$, Jane E. Harding ${ }^{1}$, Cathryn A. Conlon ${ }^{7}$, Yannan Jiang ${ }^{1,8}$ and Barbara E. Cormack ${ }^{1,2,3,4}$

\begin{abstract}
Background: Preterm birth and very small size at birth have long-term effects on neurodevelopment and growth. A relatively small percentage of extremely low birthweight babies suffer from severe neurological disability; however, up to $50 \%$ experience some neurodevelopmental or learning disability in childhood. Current international consensus is that increased protein intake in the neonatal period improves both neurodevelopment and growth, but the quantum of protein required is not known. This trial aims to assess whether providing an extra 1 to $2 \mathrm{~g} \cdot \mathrm{kg}^{-1} \cdot \mathrm{d}^{-1}$ protein in the first 5 days after birth will improve neurodevelopmental outcomes and growth in extremely low birthweight babies.
\end{abstract}

Methods/Design: The ProVIDe study is a multicentre, two-arm, double-blind, parallel, randomised, controlled trial. In addition to standard intravenous nutrition, 430 babies with a birthweight of less than $1000 \mathrm{~g}$ who have an umbilical arterial line in situ will be randomised in 1:1 ratio to receive either an amino acid solution (TrophAmine ${ }^{\oplus}$ ) or placebo (saline) administered through the umbilical arterial catheter for the first 5 days. Exclusion criteria are admission to neonatal intensive care more than $24 \mathrm{~h}$ after birth; multiple births of more than 2 babies; known chromosomal or genetic abnormality, or congenital disorder affecting growth; inborn error of metabolism, and in danger of imminent death.

Primary outcome: Survival free from neurodevelopmental disability at 2 years' corrected age, where neurodevelopmental disability is defined as cerebral palsy, blindness, deafness, developmental delay (standardised score more than 1 SD below the mean on the cognitive, language or motor subscales of the Bayley Scales of Infant Development Edition 3), or Gross Motor Function Classification System score $\geq 1$. Secondary outcomes: Growth, from birth to 36 weeks' corrected gestational age, at neonatal intensive care discharge and at 2 years' corrected age; body composition at 36 to 42 weeks' corrected postmenstrual age and at 2 years' corrected age; neonatal morbidity, including length of stay; nutritional intake.

Discussion: This trial will provide the first direct evidence of the effects of giving preterm babies a higher intake of intravenous protein in the first week after birth on neurodevelopmental outcomes at 2 years corrected age.

Trial registration: Australian New Zealand Clinical Trials Registry: ACTRN12612001084875.

Keywords: Preterm infant, Nutrition, Growth, Protein, Neurodevelopment

\footnotetext{
* Correspondence: f.bloomfield@auckland.ac.nz

${ }^{1}$ Liggins Institute, The University of Auckland, Auckland, New Zealand

${ }^{2}$ Newborn Services, Auckland City Hospital, Auckland, New Zealand

Full list of author information is available at the end of the article
} 


\section{Background}

Advances in neonatal intensive care mean that the majority of preterm babies, even at the extremes of gestation, now survive infancy, childhood and adolescence [1]. The ultimate goal for neonatal care is optimal growth, neurodevelopment and long-term health for survivors [2]. A relatively small percentage of preterm babies suffer from severe neurological impairment; however, up to $50 \%$ of extremely low birthweight (ELBW; birthweight $<1000 \mathrm{~g}$ ) babies experience some neurodevelopmental or learning impairment in childhood [3]. Current international consensus is that increased protein intake in the neonatal period improves neurodevelopment, growth, and body composition, but the quantum of protein required is not known. Therefore, it is now crucial that fundamental elements of neonatal nutrition care, such as the protein intake required for optimal growth and how this influences neurodevelopment and long-term health for preterm babies, are addressed.

The fastest rate of postnatal growth in the human lifecycle is (potentially) that of a preterm baby between 23 and 27 weeks' gestation when weight gain is approximately $21 \mathrm{~g} \cdot \mathrm{kg}^{-1} \cdot \mathrm{d}^{-1}[4]$. However, faltering growth at the equivalent gestational age is common in preterm babies $[5,6]$, due to the difficulties in providing nutrition sufficient to support this rate of growth [6,7]. Preterm babies frequently suffer both fetal and postnatal growth restriction leading to a different pattern of postnatal weight gain and body composition, including lower length at term-equivalent age, lower lean muscle mass, and higher total body fat mass [6, 8-10]. Each of these patterns of growth is associated with an increased risk of adult disease [11-13] and both fetal growth restriction and postnatal faltering growth also are associated with adverse neurodevelopmental outcome $[14,15]$.

Suboptimal nutrition likely contributes to both the faltering postnatal growth and impaired neurodevelopmental outcomes that are seen commonly in ELBW babies $[16,17]$. In preterm babies, length and head growth appear to be affected early, in contrast to the classic faltering growth of poorly nourished term infants, with Z-scores falling by 1-2 standard deviations for all measures of growth during the first month of postnatal life $[18,19]$. This early effect on head growth likely reflects the extremely rapid brain growth that occurs at the gestational ages ELBW babies are receiving suboptimal nutrition, as head circumference correlates with brain volume [20]. Volumetric magnetic resonance imaging (MRI) analyses suggest that cerebellar surface area increases 30 -fold in the last 16 weeks of pregnancy and cerebral cortical volume increases four-fold from 28 to 40 weeks' gestational age [21-23]. This very rapid development may also result in greater vulnerability to damage from less than optimal nutrition. Indeed, in adolescents born preterm, performance in final school exams and intelligence quotient (IQ) score are best predicted by the total volume of white matter in the brain detected on MRI scans, irrespective of the presence or severity of other brain abnormalities [24], with $70 \%$ of the variance in IQ explained by total white matter volume and the cross-sectional area of the corpus callosum [24].

Thus, a key modifiable factor for improving neurodevelopmental outcome in preterm babies is improving growth, especially head growth, by optimising nutritional intake in the early postnatal period. Retrospective data suggest that, across a range of protein intakes that were below international recommendations, each $1 \mathrm{~g} \cdot \mathrm{kg}^{-1} \cdot \mathrm{d}^{-1}$ increase in protein intake in the first week after birth in ELBW babies improves Mental Development Index scores by 8 points on a Bayley II assessment at 18 months [25]. However, not all data are consistent in this regard [26], few data are from robust randomised controlled trials and even fewer data are from studies in which protein and other nutrient intakes met international recommendations.

We previously have reported that babies with a birthweight of $<1200 \mathrm{~g}$ failed to meet consensus recommended intravenous nutrient intakes [7, 27-29], consistent with international experience [30,31], and that this was particularly common in ELBW babies. Close adherence to nutritional guidelines designed to increase nutritional intakes to match international recommendations does result in both increased protein intakes and significantly better growth for weight, length and head circumference, although the benefit for length growth was less than that for weight and head circumference [18]. However, despite these improvements, growth rates are still less than intrauterine growth velocity at comparable gestational ages, the currently accepted recommended goal for ELBW babies [32]. This may be because protein intake in the first week after birth remains less than estimated placental protein uptake in utero between 23 and 27 weeks' gestational age

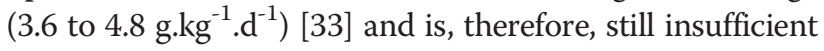
to support in utero protein accretion rates. Indeed, better linear growth is associated with higher protein intakes in the first week after birth [19]. We, therefore, hypothesise that a higher protein intake during the first week after birth will improve neurodevelopmental outcomes at age 2 years' corrected age.

In clinical practice, recommended protein intakes are difficult to achieve due to the low fluid volumes administered to ELBW babies during the first week after birth and their need for other infusions containing non-nutritive fluids such as drugs. We propose to utilise the umbilical artery catheter (UAC) to deliver additional protein, substituting the non-nutritive fluids usually given via the UAC with an 
amino acid solution. This research will fill an urgent need for data from randomised controlled trials investigating the effect of early nutritional practices on clinically important outcomes in these most vulnerable babies.

\section{Hypothesis}

The primary hypothesis is that for ELBW babies, an

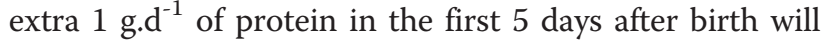
improve survival free from any neurodevelopmental disability at 2 years' corrected age. The secondary hypotheses are that increased protein intake in the first week after birth has benefits relating to neonatal morbidity, length of neonatal intensive care unit (NICU) stay, growth and body composition.

\section{Aims and objectives of this trial}

We propose replacing the non-nutritional fluids (saline) that currently are administered via the UAC with an intravenous amino acid solution and will assess the effect of this intervention through a randomised, placebo controlled trial. The aim is to determine whether an additional 1 to $2 \mathrm{~g} \cdot \mathrm{kg}^{-1} \cdot \mathrm{d}^{-1}$ protein (amino acid solution) via the UAC starting within $24 \mathrm{~h}$ of birth and continued for 5 days will (i) improve survival free of neurodisability at age 2 years' corrected; (ii) improve body composition, and (iii) prevent faltering growth at NICU discharge.

Specific aims are to determine the effect of the intervention on:

- Survival free of neurodisability at 2 years' corrected age

- Growth, from birth to 36 weeks' postmenstrual age, at NICU discharge and at 2 years' corrected age.

- Body composition, at 36 weeks' postmenstrual age measured by air displacement plethysmography, and at 2 years' corrected age

- Neonatal morbidity, including length of stay

- Nutritional intake

\section{Methods/Design}

Trial design

Multicentre, double-blind, two-arm, parallel, randomised, controlled trial.

\section{Ethical approval}

The Northern B Health and Disability Ethics Committee has given ethical approval for this study (No 13/NTB/84), and each participating site has institutional approval through local institutional review processes. The New Zealand National Screening Unit has given approval for access to the Newborn Metabolic Screening data.

\section{Inclusion criteria}

Babies with a birthweight of less than $1000 \mathrm{~g}$ who have a UAC in situ in an acceptable position.

\section{Exclusion criteria}

Babies admitted to neonatal intensive care more than $24 \mathrm{~h}$ after birth; multiple births of more than 2 babies; known chromosomal or genetic abnormality, or congenital disorder affecting growth; inborn error of metabolism; in danger of imminent death.

\section{Trial entry and randomisation}

Parents will be given a written information sheet about the study antenatally (where possible), which will be reviewed with them by a member of the study team. If birth occurs without time for this to happen, information will be given to the parents as soon as is feasible after birth and reviewed with them by a member of the study team. Within $24 \mathrm{~h}$ of birth and once a UAC has been placed, eligible babies will be randomised to either the placebo group or the intervention group. Babies for whom it was not possible to obtain consent antenatally will be enrolled based on a waiver of consent (approved by the ethics committee) with a requirement that informed, written consent is obtained within $24 \mathrm{~h}$. If consent is not obtained within $24 \mathrm{~h}$ of randomisation, the baby will be withdrawn from the study.

\section{Study groups and management}

Babies in the placebo group will receive $0.45 \%$ saline through the UAC (standard therapy). Babies in the intervention group will receive an amino acid solution (8.5\% TrophAmine ${ }^{\circledR}$, B Braun Medical, Irvine, USA) through the UAC giving an extra 1 g. $\mathrm{d}^{-1}$ of protein above standard intravenous nutrition. Babies in both groups will receive routine neonatal care including intravenous and enteral nutrition according to each centre's practice.

\section{Randomisation}

Within $24 \mathrm{~h}$ of birth and once a UAC has been placed in an acceptable position, babies will be enrolled by medical and research staff and randomly allocated in a 1:1 ratio to treatment and placebo groups via a web-based interface maintained and concealed by an independent database controller. Twins will be randomised as separate babies. Randomisation will be stratified for recruitment centre (each centre has different nutrition practices), sex and appropriate-for-gestational-age/small-for-gestationalage status (these variables influence growth and body composition), using blocked randomisation with variable block sizes.

\section{Blinding}

Subjects and their families, clinical staff, investigators and assessors at follow up appointments will be blinded to treatment allocation throughout the entire study. Intervention and placebo fluids will be made by an independent contractor and will be identical in appearance 
and identified only by a randomly generated numerical identifier. Composition of the fluid in each bag will be known only by the independent database controller. Unblinding should occur only in exceptional circumstances when knowledge of the actual treatment is absolutely essential for further management of the patient. If unbinding is deemed to be necessary by a neonatologist, the neonatologist is encouraged to discuss this with the overall responsible investigator (FHB). The actual allocation will not be disclosed to parents and/or other study personnel. Any code break that occurs will be reported to the principal investigator and Steering Group without identifying treatment allocation.

\section{Intervention}

All babies will receive nutrition according to individual neonatal intensive care unit practices. In addition, babies will be randomised to one of two groups:

Treatment group: Babies will receive an infusion of $8.5 \%$ TrophAmine ${ }^{\circ}$ at $0.5 \mathrm{ml}^{-1}$ via the UAC, providing $1 \mathrm{~g}$ protein in $12 \mathrm{ml}$ or $1-2 \mathrm{~g} \cdot \mathrm{kg}^{-1} \cdot \mathrm{d}^{-1}$ additional protein, depending on birthweight. Placebo group: Babies will receive an infusion of $0.45 \%$ saline at $0.5 \mathrm{ml}^{-1}$ via a UAC (current standard practice). Both solutions will contain heparin $0.5 \mathrm{iU} \cdot \mathrm{ml}^{-1}$. The intervention will continue for $120 \mathrm{~h}$.

\section{Blood sample analysis}

Routine biochemical monitoring will take place in accordance with local guidelines. Concentrations of potassium, $\mathrm{pH}$, bicarbonate, base excess and lactate will be recorded daily. In addition, blood samples will be collected on day 1 (24 h after UAC infusion starts) and day 5 (after the UAC study fluids cease) for the measurement of serum concentrations of urea, albumin, total protein, globulin, calcium and phosphate concentrations on days 1 and 5, and ammonia concentration on day 5. Study blood results will not be revealed to attending physicians.

\section{Newborn metabolic screening}

Blood spots taken for routine Newborn Metabolic Screening will be taken immediately before and after the 5 -day intervention period. Consent has been granted by the New Zealand National Screening Unit for access to the Newborn Metabolic Screening data, including amino acid and acyl carnitine concentrations.

\section{Monitoring of nutritional intake}

Total enteral and intravenous intakes will be recorded daily until day 28. Mean daily protein, energy and other nutrient intakes will be calculated based on actual intakes. Full enteral feeds will be defined as the day when no further intravenous nutrition is given or $150 \mathrm{ml} . \mathrm{kg}^{-1} \mathrm{~d}^{-1}$ enteral feeds is reached. Energy and protein intakes will be calculated using preterm transitional breast-milk composition for the first 2 weeks $(65 \mathrm{kcal}$ and $1.5 \mathrm{~g}$ protein. $100 \mathrm{ml}^{-1}$ ) and mature breastmilk composition thereafter $\left(72 \mathrm{kcal}\right.$ and $1.2 \mathrm{~g}$ protein. $\left.100 \mathrm{ml}^{-1}\right)$ [34-38].

\section{Participant withdrawal}

Development of significant renal impairment (serum creatinine $>130 \mu \mathrm{mol}^{-1} \mathrm{l}^{-1}$ ) or diagnosis of an inborn error of metabolism requiring prescribed protein intakes will result in the intervention being discontinued. Participants will be withdrawn from the trial at parental request or if the attending physician determines that this is essential for the baby's care. Consent will be requested to continue to use routinely collected data for study purposes.

\section{Study outcomes \\ Primary outcome}

The primary outcome will be survival free from any neurodevelopmental disability at 2 years' corrected age. Assessment will include the Bayley Scales of Infant Development Edition 3 (Bayley III), neurodevelopment, growth and body composition. Cerebral palsy (loss of motor function and abnormalities of muscle tone and power) and other impairment outcomes will be assessed according to previously reported criteria [39]. The severity of gross motor function will be classified using the Gross Motor Function Classification System [40]. Children with severe developmental delay who are unable to complete the psychological assessment will be given a standardised score of - 4 SD. Children will be considered blind if visual acuity in both eyes is worse than $6 / 60$ and deaf if their hearing loss is sufficient to require hearing aid(s), or worse.

Children will be considered to have a neurodevelopmental disability if they have cerebral palsy, a gross motor classification score $\geq 1$ [40], blindness, deafness or developmental delay, defined as a standardised score for cognitive, motor or language scales more than $1 \mathrm{SD}$ below the mean [41]. The neurodevelopmental disabilities imposed by the various neurodevelopmental impairments will be classified as severe, moderate or mild [39].

\section{Secondary outcomes}

Growth Weight, length and head circumference will be measured at birth, 28 days, 8 and 36 weeks' postmenstrual age, and at discharge. Weight, height and head circumference will be measured at 2 years' corrected age. All measurements will be by trained staff using validated, repeatable methods $[42,43]$. All growth data Z-scores will be calculated individually for each baby using appropriate normative data. Growth velocity (GV) will be calculated 
using: $\mathrm{GV}=[1000 \times \ln (\mathrm{Wn} / \mathrm{W} 1)] /(\mathrm{Dn}-\mathrm{D} 1)$ where $\mathrm{W}=$ weight (g) and $\mathrm{D}=$ day after birth on days $\mathrm{n}$ (end of time interval) and 1 (beginning of time interval) [44].

Body composition Body composition, where possible, will be measured by air displacement plethysmography at 36 to 42 weeks' post-menstrual age and at 2 years' corrected age.

Neonatal outcomes The presence of morbidities at 36 weeks' post-menstrual age, including intraventricular haemorrhage (IVH), severe IVH (Grade 3 or 4 defined using the grading system from Papile et al. [45]), periventricular leukomalacia, chronic lung disease (need for oxygen at 36 weeks' post-menstrual age or 28 days after birth if born after 32 weeks' gestation), retinopathy of prematurity grades 3 and 4 as per the International Classification of Retinopathy of Prematurity [46], necrotising enterocolitis (defined as Bell's stage 2 or higher [47]), patent ductus arteriosus diagnosed by echocardiography needing treatment, length of NICU stay and late-onset sepsis (beyond 7 days after birth and defined as a positive bacterial culture in cerebrospinal fluid, urine or blood with clinical signs of infection and with antibiotics for 5 or more days with the intention of treating an infection, or treatment for a shorter period if the patient died. If after 10 days of appropriate antibiotic therapy there was demonstration of sterile culture and then the same organism was cultured or if a different organism was cultured from a subsequent culture, this will be considered an additional episode).

Nutritional intake Intravenous and enteral nutritional intake until 28 days (fluid, energy, protein, fat, carbohydrate, vitamins and minerals). Feed type and nutritional supplementation at NICU discharge.

\section{Statistical considerations}

Sample size A total of 430 babies $(n=215$ in each group) will provide $85 \%$ power at a $5 \%$ level of significance (two-sided), to detect an absolute difference of $15 \%$ in survival free of disability between the two groups at 2 years' corrected age. The sample size has taken into account a $10 \%$ loss to follow up rate and a disability rate in the control group of $50 \%$.

Statistical analyses Statistical analyses will be performed on an intention-to-treat basis. Missing outcome data will not be imputed in the primary analysis, as the key assumption of missing at random is not likely to hold in the analysis population. Sensitivity analyses will be conducted, however, using multiple imputations method to explore the potential impact of missing data on outcomes. The characteristics of those participants with missing data will be compared between two treatment groups. Per protocol analysis will be performed for those who received at least $80 \%$ of the intended treatment. Sub-group analysis will be conducted on the treatment outcomes in relation to total protein received and to the extra study dose received. Statistical tests will be two-sided at a $5 \%$ significance level. Twins will be randomised as separate babies, with the non-independence of these pairs taken into account during analysis.

Baseline characteristics of all randomised babies and their mothers will be summarised for each group as well as overall using descriptive statistics. Continuous variables will be reported as numbers of observed and missing values, mean, standard deviation, median and range. Categorical variables will be described as frequencies and percentages. The primary outcome, survival free of disability, will be first presented as unadjusted relative risk (RR) with $95 \%$ confidence interval (CI). Generalised linear regression models appropriate to continuous and categorical outcomes will be used to evaluate the treatment difference between two groups, adjusting for stratification variables and other baseline confounders that are closely associated with the outcomes (e.g. birth weight, sex and treatment with antenatal steroids). Adjusted RRs and $95 \%$ CIs will be estimated using a log link. Analyses of growth outcomes will be performed following completion of NICU discharge assessments but will not be revealed to assessors of the Bayley III at 2 years' corrected age.

Data monitoring and other quality control measures A Trial Steering Committee has been formed to monitor the conduct of the study. The terms of reference were agreed at the first meeting (before the trial began). Trial procedures will be in accordance with the CONSORT guidelines $[48,49]$. The Trial Steering Committee is responsible for advising investigators regarding trial continuation or cessation should issues of futility or safety arise, and meet within a month of all Data Monitoring Committee meetings to consider their recommendations.

The terms of reference for an independent Data Monitoring Committee were agreed at the first meeting. An independent Safety Monitoring Committee has also been formed. During the period of recruitment, aggregated summaries of death or other serious adverse event that the local investigator believes should be referred will be supplied, in strict confidence, to the Safety Monitoring Committee. The Safety Monitoring Committee will review individual reports of adverse events. Group allocation will not be revealed to the Safety Monitoring Committee or the investigators. Should the Safety Monitoring Committee rule that the intervention may have impacted on the adverse outcome, this will be 
immediately reported to the chair of the Trial Steering Committee. The Steering Committee will decide on the actions to be taken.

\section{Discussion}

This multicentre randomised controlled clinical trial aims to assess whether a higher protein intake in the first 5 days after birth will improve survival free of disability in extremely low birthweight babies. Until data from large, well-designed randomised trials are available to assess the effects of earlier higher intravenous protein intakes it is difficult to develop meaningful, evidence-based nutrition guidelines. A conclusive outcome will provide important, reliable evidence of great relevance for the nutritional management all preterm babies $<1000 \mathrm{~g}$ at birth in settings where intensive care and intravenous nutrition are provided, because it involves administering additional protein through the simple substitution of one fluid for another using an existing commercial amino acid solution.

This intervention has the potential to improve significantly both short and long-term health outcomes for preterm babies and, therefore, to reduce health costs for these children as they reach adolescence and adulthood. If successful this simple, readily available and low cost intervention is likely to result in a rapid change in international practice, benefiting preterm babies worldwide.

\footnotetext{
Abbreviations

ELBW: Extremely low birthweight; UAC: Umbilical arterial catheter; Bayley III: Bayley Scales of Infant Development Third Edition Bayley III;

NICU: Neonatal intensive care unit; Z-score: Standard deviation score; MRI: Volumetric magnetic resonance imaging; IQ: Intelligence quotient; Cl: Confidence interval.
}

\section{Competing interests}

The authors declare they have no competing interests.

\section{Authors' contributions}

BEC conceived the study concept. BEC, FHB, CAC, JEH participated in drafting the trial protocol. JY oversaw sample size determination and the statistical analysis plan. FHB and JEH obtained funding. BEC and FHB obtained ethical approvals. BEC and FHB drafted the manuscript and all authors read and approved the final manuscript.

\footnotetext{
Acknowledgements

The authors would sincerely like to thank the ProviDe investigators at each recruitment centre for their support:

Roland Broadbent - Neonatal Intensive Care Unit, Dunedin Hospital, Dunedin 9016, New Zealand

Adrienne Lynn - Neonatal Intensive Care Unit, Christchurch Women's Hospital, Christchurch 8011, New Zealand; Michael Hewson - Neonatal Intensive Care Unit, Wellington Regional Hospital, Wellington 6021, New Zealand; Arun Nair - Neonatal Intensive Care Unit, Waikato Hospital, Hamilton 3240, New Zealand, and Mike Meyer - Neonatal Intensive Care Unit, KidzFirst, Middlemore Hospital, Auckland 2025, New Zealand

The trial protocol was presented to, and peer-reviewed by, the PSANZ IMPACT Network for improving mothers' and babies' health. We would also like to acknowledge: Ellen Campbell and Safayet Hossin for their help with study coordination and the randomisation database; Dianne Webster and Emma Glamuziuna for contributions to Newborn Screening data; NZ neonatologists and nurses for assisting with the study design and sharing of local nutritional data, and Massey University for the use of their air displacement plethysmograph.
}

\section{Funding}

The ProVIDe study has been funded by the Health Research Council of New Zealand, Gravida: National Centre for Growth and Development, A+ Trust, Cure Kids, Lottery Grants Board and the Nurture Foundation.

\section{Author details}

${ }^{1}$ Liggins Institute, The University of Auckland, Auckland, New Zealand. ${ }^{2}$ Newborn Services, Auckland City Hospital, Auckland, New Zealand. ${ }^{3}$ Gravida: National Centre for Growth and Development, Auckland, New Zealand. ${ }^{4}$ Auckland Academic Health Alliance, Auckland, New Zealand. ${ }^{5}$ Department of Paediatrics: Child and Youth Health, The University of Auckland, Auckland, New Zealand. ${ }^{6}$ The Robinson Institute, The University of Adelaide, Adelaide, Australia. ${ }^{7}$ School of Food and Nutrition, College of Health, Massey University, Auckland, New Zealand. ${ }^{8}$ Department of Statistics, Faculty of Science, The University of Auckland, Auckland, New Zealand.

Received: 31 March 2015 Accepted: 16 July 2015

Published online: 26 August 2015

\section{References}

1. Stoelhorst GM, Rijken M, Martens SE, Brand R, den Ouden AL, Wit JM, et al. Changes in neonatology: comparison of two cohorts of very preterm infants (gestational age <32 weeks): the Project On Preterm and Small for Gestational Age Infants 1983 and the Leiden Follow-Up Project on Prematurity 1996-1997. Pediatrics. 2005;115(2):396-405.

2. Ong KK. Catch-up growth in small for gestational age babies: good or bad? Curr Opin Endocrinol Diabetes Obes. 2007;14(1):30-4.

3. Moore T, Hennessy EM, Myles J, Johnson SJ, Draper ES, Costeloe KL, et al, Neurological and developmental outcome in extremely preterm children born in England in 1995 and 2006: the EPICure studies. BMJ. 2012;345, e7961.

4. Kramer MS, Platt RW, Wen SW, Joseph KS, Allen A, Abrahamowicz M, et al. A new and improved population-based Canadian reference for birth weight for gestational age. Pediatrics. 2001;108(2):E35.

5. Cormack BE, Bloomfield FH, Dezoete A, Kuschel CA. Does more protein in the first week of life change outcomes for very low birthweight babies? J Paediatr Child Health. 2011;47(12):898-903.

6. Cole TJ, Statnikov Y, Santhakumaran S, Pan H, Modi N. Postnatal weight gain after very preterm birth: a UK population study. Arch Dis Child. 2011;96 Suppl 1:A3-4.

7. Cormack BE, Bloomfield FH. Audit of feeding practices in babies $<1200 \mathrm{~g}$ or 30 weeks gestation during the first month of life. J Paediatr Child Health. 2006:42(7-8):458-63.

8. Fanaroff AA, Stoll BJ, Wright LL, Carlo WA, Ehrenkranz RA, Stark AR, et al. Trends in neonatal morbidity and mortality for very low birthweight infants. Am J Obstet Gynecol. 2007;196(2):147 e141-148.

9. Roggero P, Gianni ML, Amato O, Orsi A, Piemontese P, Morlacchi L, et al. Is term newborn body composition being achieved postnatally in preterm infants? Early Human Dev. 2009;85(6):349-52.

10. Uthaya S, Thomas EL, Hamilton G, Dore CJ, Bell J, Modi N. Altered adiposity after extremely preterm birth. Pediatr Res. 2005;57(2):211-5.

11. Rotteveel J, van Weissenbruch MM, Twisk JW, Delemarre-Van de Waal HA. Infant and childhood growth patterns, insulin sensitivity, and blood pressure in prematurely born young adults. Pediatrics. 2008;122(2):313-21.

12. Pilling EL, Elder CJ, Gibson AT. Growth patterns in the growth-retarded premature infant. Best Pract Res Clin Endocrinol Metab. 2008;22(3):447-62.

13. Chernausek SD. Update: consequences of abnormal fetal growth. J Clin Endocrinol Metab. 2012;97(3):689-95.

14. Casey PH, Whiteside-Mansell L, Barrett K, Bradley RH, Gargus R. Impact of prenatal and/or postnatal growth problems in low birth weight preterm infants on school-age outcomes: an 8-year longitudinal evaluation. Pediatrics. 2006;1 18(3):1078-86.

15. Ehrenkranz RA, Dusick AM, Vohr BR, Wright LL, Wrage LA, Poole WK. Growth in the neonatal intensive care unit influences neurodevelopmental and growth outcomes of extremely low birth weight infants. Pediatrics. 2006;117(4):1253-61.

16. Ziegler EE. Meeting the nutritional needs of the low-birth-weight infant. Ann Nutr Metab. 2011;58 Suppl 1:8-18.

17. Corpeleijn WE, Vermeulen MJ, van den Akker CH, van Goudoever JB. Feeding very-low-birth-weight infants: our aspirations versus the reality in practice. Ann Nutr Metab. 2011;58 Suppl 1:20-9. 
18. Cormack BE, Bloomfield FH. Increased protein intake decreases postnatal growth faltering in ELBW babies. Arch Dis Child Fetal Neonatal Ed. 2013;98(5):F399-404.

19. Cole TJ, Williams AF, Wright CM. Revised birth centiles for weight, length and head circumference in the UK-WHO growth charts. Ann Human Biol. 2011;38(1):7-11.

20. Cheong JL, Hunt RW, Anderson PJ, Howard K, Thompson DK, Wang HX, et al. Head growth in preterm infants: correlation with magnetic resonance imaging and neurodevelopmental outcome. Pediatrics. 2008;121(6):e1534-40.

21. Huppi PS, Warfield S, Kikinis R, Barnes PD, Zientara GP, Jolesz FA, et al. Quantitative magnetic resonance imaging of brain development in premature and mature newborns. Ann Neurol. 1998;43(2):224-35.

22. Kostovic I, Judas M, Rados M, Hrabac P. Laminar organization of the human fetal cerebrum revealed by histochemical markers and magnetic resonance imaging. Cereb Cortex. 2002;12(5):536-44.

23. Kapellou O, Counsell SJ, Kennea N, Dyet L, Saeed N, Stark J, et al. Abnormal cortical development after premature birth shown by altered allometric scaling of brain growth. PLoS Med. 2006;3(8):e265.

24. Northam GB, Liegeois F, Chong WK, Wyatt JS, Baldeweg T. Total brain white matter is a major determinant of IQ in adolescents born preterm. Ann Neurol. 2011;69(4):702-11.

25. Stephens BE, Walden RV, Gargus RA, Tucker R, McKinley L, Mance M, et al. First-week protein and energy intakes are associated with 18-month developmental outcomes in extremely low birth weight infants. Pediatrics. 2009;123(5):1337-43.

26. Blanco CL, Gong AK, Schoolfield J, Green BK, Daniels W, Liechty EA, et al. Impact of early and high amino acid supplementation on ELBW infants at 2 years. J Pediatr Gastroenterol Nutr. 2012;54(5):601-7.

27. Tsang RC, Uauy R, Koletzko B, Zlotkin SH. Nutrition of the Preterm Infant: Scientific Basis and Practical Guidelines. 2nd ed. Cincinnati: Digital Education Publishing, Inc.; 2005.

28. Koletzko B, Goulet O, Hunt J, Krohn K, Shamir R. Guidelines on paediatric parenteral nutrition of the European Society of Paediatric Gastroenterology, Hepatology and Nutrition (ESPGHAN) and the European Society for Clinical Nutrition and Metabolism (ESPEN), Supported by the European Society of Paediatric Research (ESPR). J Pediatr Gastroenterol Nutr. 2005;41 Suppl 2:S1-87.

29. Agostoni C, Buonocore G, Carnielli VP, De Curtis M, Darmaun D, Decsi T, et al. Enteral nutrient supply for preterm infants: commentary from the European Society of Paediatric Gastroenterology, Hepatology and Nutrition Committee on Nutrition. J Pediatr Gastroenterol Nutr. 2010;50(1):85-91.

30. Lapillonne A, Carnielli VP, Embleton ND, Mihatsch W. Quality of newborn care: adherence to guidelines for parenteral nutrition in preterm infants in four European countries. BMJ Open. 2013:3(9):e003478.

31. Stewart JAD, Mason DG, Smith N, Protopapa K, Mason M. A Mixed Bag: An enquiry into the care of hospital patients receiving parenteral nutrition. London: NCEPOD; 2010. p. 31-52.

32. American Academy of Pediatrics Committee on Nutrition. Nutritional needs of the preterm infant. In: Pediatric Nutrition Handbook. 5th ed. llinois: American Academy of Pediatrics; 2003. p. 23.

33. Hay Jr WW, Lucas A, Heird WC, Ziegler E, Levin E, Grave GD, et al. Workshop summary: nutrition of the extremely low birth weight infant. Pediatrics. 1999;104(6):1360-8.

34. Lonnerdal B, Forsum E, Hambraeus L. A longitudinal study of the protein, nitrogen, and lactose contents of human milk from Swedish well-nourished mothers. Am J Clin Nutr. 1976;29(10):1127-33.

35. Anderson $\mathrm{GH}$, Atkinson SA, Bryan MH. Energy and macronutrient content of human milk during early lactation from mothers giving birth prematurely and at term. Am J Clin Nutr. 1981;34(2):258-65.

36. Fomon SJ. Requirements and recommended dietary intakes of protein during infancy. Pediatr Res. 1991;30(5):391-5.

37. Butte NF, Garza C, Johnson CA, Smith EO, Nichols BL. Longitudinal changes in milk composition of mothers delivering preterm and term infants. Early Human Dev. 1984;9(2):153-62.

38. Arslanoglu S, Moro GE, Ziegler EE. Preterm infants fed fortified human milk receive less protein than they need. J Perinatol. 2009;29(7):489-92.

39. Doyle LW. Changing availability of neonatal intensive care for extremely low birthweight infants in Victoria over two decades. Med J Aust. 2004;181(3):136-9.

40. Palisano R, Rosenbaum P, Walter S, Russell D, Wood E, Galuppi B. Development and reliability of a system to classify gross motor function in children with cerebral palsy. Dev Med Child Neurol. 1997;39(4):214-23.
41. Bayley N. Bayley Scales of Infant and Toddler Development Administration Manual. 3rd ed. San Antonio, TX: Harcourt Assessment; 2006.

42. Davies DP, Holding RE. Neonatometer: a new infant length measurer. Arch Dis Child. 1972:47(256):938-40.

43. Shaw $V$, Lawson M. Nutritional assessment, dietary requirements, feed supplementation. In: Shaw V, Lawson M, editors. Clinical Paediatric Dietetics. 3rd ed. Oxford: Blackwell Publishing; 2007. p. 3-20.

44. Patel AL, Engstrom JL, Meier PP, Kimura RE. Accuracy of methods for calculating postnatal growth velocity for extremely low birth weight infants. Pediatrics. 2005;116(6):1466-73.

45. Papile LA, Burstein J, Burstein R, Koffler $\mathrm{H}$. Incidence and evolution of subependymal and intraventricular hemorrhage: a study of infants with birth weights less than 1,500 gm. J Pediatr. 1978;92(4):529-534.

46. The International Classification of Retinopathy of Prematurity revisited. Arch Ophthalmol. 2005:123(7):991-999.

47. Bell MJ, Ternberg JL, Feigin RD, Keating JP, Marshall R, Barton L, et al. Neonatal necrotizing enterocolitis. Therapeutic decisions based upon clinical staging. Ann Surg. 1978;187(1):1-7.

48. Moher D, Hopewell S, Schulz KF, Montori V, Gotzsche PC, Devereaux PJ, et al. CONSORT 2010 explanation and elaboration: updated guidelines for reporting parallel group randomised trials. Int J Surg. 2012;10(1):28-55.

49. Schulz KF, Altman DG, Moher D. CONSORT 2010 statement: updated guidelines for reporting parallel group randomised trials. Int J Surg. 2011;9(8):672-677.

\section{Submit your next manuscript to BioMed Central and take full advantage of:}

- Convenient online submission

- Thorough peer review

- No space constraints or color figure charges

- Immediate publication on acceptance

- Inclusion in PubMed, CAS, Scopus and Google Scholar

- Research which is freely available for redistribution 